\title{
MATE SELECTION PREFERENCES BASED ON ALTRUISTIC CHARACTERISTICS AMONG THAIS
}

\author{
Somying Tsai* \\ Independent Researcher \\ Email: angelatsaii0224@gmail.com
}

\begin{abstract}
Douglas Rhein**
Faculty of Social Science, Mahidol University International College, 999 Bhuddamonthon 4 Rd. Salaya, Nakhon Pathom, Thailand

Email: Douglas.rhe@mahidol.edu
\end{abstract}

Published online: 25 January 2022

To cite this article: Tsai, S. and Rhein, D. 2022. Mate selection preferences based on altruistic characteristics among Thais. International Journal of Asia Pacific Studies 18 (1): 107-123. https://doi.org/10.21315/ijaps2022.18.1.5

To link to this article: https://doi.org/10.21315/ijaps2022.18.1.5

\begin{abstract}
Extensive research in evolutionary psychology has explored the role that altruism plays in mate preference. This research aims to investigate whether altruism is desired for long-term and short-term relationships among females and males, as well as to determine potential sex differences within this preference among Thai nationals. To that end, a self-administered online Thai language-based survey was distributed for data collection; 138 Thai respondents (mean age $=22.5$, SD $=4.37$ ) completed the survey. The respondents were asked to read nine hypothetical scenarios and rate their preferences for different individuals in the scenarios for long-term and shortterm relationships. In each scenario, if one person displayed high levels of altruism, another person in the same scenario would display a lower level of altruism. A $2 \times 2 \times 2$ mixed ANOVA indicated that both men and women significantly favoured altruistic partners for long-term relationships; whereas, when displays of altruism was low, there was only a slight difference in preference for a short-term or longterm relationship. Moreover, there was no significant difference between men and women's desirability for altruistic partners. This study provides further support for previous altruism-based research which emphasises the importance of altruism regarding long term mate selection.
\end{abstract}

Keywords: Mate selection, preference, altruism, pro-sociality, relationship

(C) Penerbit Universiti Sains Malaysia, 2022. This work is licensed under the terms of the Creative Commons Attribution (CC BY)(https://creativecommons.org/licenses/by/4.0/). 


\section{INTRODUCTION}

Altruism refers to acts that improve the welfare of another individual at the cost to the actor's own fitness (Wilson 2015). Enhancing the fitness of others often involves costs such as time, energy, or personal safety. There is evidence supporting a long evolutionary history of altruism. Social exchange is a form of cooperation that can be observed across human societies and is discovered frequently in hunting-gathering societies that are believed to resemble ancestral states (Lee and DeVore 1968). Many evolutionary biologists have proposed that the ability to hunt better game was the first essential and significant act of cooperation (Pfaff 2015). However, from an evolutionary approach, helping non-relatives is somewhat puzzling. Natural selection proposed by Charles Darwin explains that the fittest individuals of an environment possess heritable characteristics that increase their survival and reproduction at a higher rate than those without these characteristics (Campbell et al. 2015). So, if altruism enhances the fitness of another individual with a cost to the altruist, how could altruism possibly evolve? There are various evolutionary mechanisms such as reciprocal altruism and group selection that explain altruism among non-relatives. Trivers (1971) developed the theory of reciprocal altruism in an attempt to explain altruism towards non-kin. Trivers' theory suggests that when an individual receives a favour from an altruist, the individual returns the favour (reciprocation), then, the altruist is also more likely to do more favours in return (reinforcement). The act of helping others is costly, but it is beneficial if there is a reverse situation where the individual who was helped before may act altruistically towards the individual who helped them initially. Alternatively, group selection theory proposes that an individual would help others in the same group in order to increase the survival fitness of the whole group (Pfaff 2015). Thus, both the altruists and their kin would have a higher chance to pass their genes. However, neither theories explain greater philanthropic altruism such as giving money to beggars which results in low rates of direct reciprocity. Therefore, evolutionary psychologists have suggested that sexual selection might be a more appropriate explanation.

"The sight of a feather in a peacock's tail, whenever I gaze at it, makes me sick," this comment by Charles Darwin was the beginning of the theory of sexual selection (Cronin 1993). Darwin developed this theory when he noticed certain characteristics were costly and had no survival value such as the bright colour of the peacock's tail which might attract predators (Campbell et al. 2015). The theory of sexual selection explored the adaptations 
and characteristics that evolved as a result of successful mating, rather than survival (Darwin 1874). Like the peacock's tail, males with the showiest and fancy tails would be favoured by the females and chosen as mates (Darwin 1874). Darwin's peacock tail conundrum is similar to the altruism in mate selection issue in that it is an important, yet counterintuitive, aspect of sexual selection. Importantly, sexual selection can lead to greater evolutionary variations and subsequent niche occupation. The characteristics that win a competition and result in mating success will be passed to the next generation in greater numbers (Buss 2015). There are certain features that are more desired when seeking a mate which leads to the rise in the frequency of these desired features. Similarly, the decreasing frequency of undesired features in the genome creates evolutionary changes (Buss 2015).

Extensive research indicates altruism may act as the peacock's tail and that women, more than men, place a greater significance on altruistic traits during mate selection. Studies have found that more females than males considered altruistic behaviours as attractive traits (Phillips et al. 2008; Arnocky et al. 2017). Indeed, men reported being more altruistic and cooperative when looking at a physically attractive female photo (Bhogal et al. 2016). Goldberg (1995) investigated sex differences between people who gave money to beggars and found that a disproportionate number of single men gave money to female beggars. Moreover, Latane (1970) found that when a female companion was present, men were more likely to give to both male and female beggars. Men, more than women, also preferred to perform altruistic behaviour that demonstrated physical bravery as these acts provided cues associated with their physical ability and the willingness to help others even when facing risk (Iredale and Vugt 2009). Barclay (2010) suggested that altruism functions as a courtship display, especially by males. Phillips et al. (2008) developed a psychometric scale to measure mate desirability towards altruistic behaviours and found that females expressed a stronger desirability towards altruism. In sum, the aforementioned literature suggests, specifically in regard to altruism, that there is a significant gender difference during mate selection.

The degree of preference for an altruistic mate also seems to vary according to the length of the relationship. A study found that female desirability for altruistic traits is greater in long-term relationships (Margana et al. 2019). Farrelly et al. (2016) examined the interaction between altruism and physical attractiveness in mate selection and found that females did not only prefer altruistic males in long-term relationships but being more altruistic made less attractive males become more desirable for long-term relationships. 
Barclay (2010) also showed that altruists were more attractive in long-term relationships when compared to neutral individuals. A similar result was found by Moore et al. (2013) who concluded that helping behaviours correlated with an increase in the preference of both men and women as long-term mates.

To date, most of the studies about mate selection and sexual preferences based on altruistic traits have been conducted in Western, educated, industrialised, rich, and democratic (WEIRD) nations. However, the cultural element is crucial for generalisations and developing a universal perspective, not just in terms of understanding mate selection, but for evolutionary psychology as a whole. An important motivation behind this study is to determine if there is a potential different response pattern in relation to mate selection and altruistic behaviours. The exploration of the role of altruism and mate selection within the unique culture of Thailand will expand the current knowledge beyond the confinements of WEIRD contexts. Therefore, a reconstructed methodology based on Margana et al. (2019) was used to explore Thais' preference for altruistic partners, the influences of relationship types on this preference, as well the possible gender differences in selection for altruistic traits. This study is similar to Farrelly and King (2019) as it did not include the role of heroism in the mate selection process.

\section{HYPOTHESES}

Based on the current literature, the first hypothesis is that Thais will prefer altruistic mates over non-altruistic individuals. The second hypothesis is that this preference will increase in long-term relationships but not in short-term relationships. The third hypothesis is that females more than males will place a greater significance on altruism when evaluating potential mates.

\section{MATERIALS AND METHODS}

\section{Participants}

The target population was Thais, while the sample population primarily consisted of both male and female university students. One hundred and forty four respondents were recruited by using convenience and snowball sampling methods. Participants were required to read and acknowledge an informed consent document prior to initiating the survey instructions. Respondents were excluded from statistical analysis if they were not Thais, did not complete the 
voluntary consent form or did not complete the entire survey. Given the above requirements, of the 144 surveys returned to the researchers, 138 respondents (65 males and 73 females; mean age $=22.5, \mathrm{SD}=4.37$ ) were included in the statistical analysis. This research was approved by and followed the guidelines set by the Institutional Review Board at Mahidol University.

\section{DESIGN}

The current research is a reconstructed study design based on Margana et al. (2019). As such, this research constructed a similar but modified Thai participant self-administered online-based survey. The first section contained demographic questions related to the respondents' age, current status (undergraduates/postgraduates/employees), ethnicity (Thai/Indian/Chinese, etc.), current institution, and sex (male/female).

Before the respondents proceeded to the second section, they were informed of the definitions of short-term and long-term relationships. The definitions were translated from the definitions given by Margana et al. (2019). The second section consisted of nine vignettes. Each was followed by a 5-point Likert scale $(1=$ not very likely to $5=$ very likely). After reading each vignette, respondents were asked to rate how desirable person " $\mathrm{X}$ " and " $Y$ " are for a long-term and a short-term relationship. Even though the inspiration of the current study came from Margana et al. (2019), the direction of the two studies was different. Margana et al. (2019) examined the roles of altruism, heroism, and physical attractiveness in female mate choice. However, the current study focused solely on altruism, and both males and females were recruited. The context of every vignette was also rewritten in order to adapt to Thai social norms.

This study adopted a 2 (altruism: high and low) $\times 2$ (relationship types: long-term and short-term) $\times 2$ (sex: male and female) mixed analysis of variance (ANOVA). This is a three-way interaction ANOVA because there are three variables (sex, altruism, and relationship type). The within-subject factors were the level of altruism (high vs. low) and the preference for a relationship, which was rated using a 5-point Likert-type scale. The betweensubject factor was the sex of the respondents, as the research was comparing responses from males and females. Nine hypothetical vignettes were given to the respondents, each consisting of different altruistic behaviours. In each vignette, there were two people performing different levels of altruism (high versus low). For example, if a person " $\mathrm{X}$ " exhibited a high level of altruism, 
the person "Y" in the same vignette would display a lower level of altruism. Respondents were required to read each vignette carefully and underneath each vignette, respondents were asked to rate how desirable person " $\mathrm{X}$ " and "Y" are for a long-term and a short-term relationship.

\section{DATA ANALYSIS}

The data were analysed using SPSS. Cronbach's alpha was carried out to confirm the coefficient for internal consistency reliability for Likert-type scales (Gliem and Gliem 2003). A three-way mixed ANOVA was performed in order to investigate the association between altruism and desirability for short-term and long-term relationships, as well as potential sex differences. In all cases, a $p$-value $<0.05$ was considered statistically significant.

\section{RESULTS}

In this study, Cronbach's alpha was applied to four scales, and each scale comprised nine vignettes. In the three scales (low altruism in short-term relationship, low altruism in long-term relationship, and high altruism in short-term relationship), Cronbach's alpha showed the scales had acceptable reliability, $\alpha=0.713, \alpha=0.710$, and $\alpha=0.788$, respectively (see Table 1 ). However, the last scale (high altruism in long-term relationship) showed excellent reliability as $\alpha=0.920$. The rules of thumb were given by George and Mallery (2003).

Table 1: Reliability statistics of four scales from Cronbach's alpha

\begin{tabular}{lccc}
\hline Scales & Cronbach's alpha & $\begin{array}{c}\text { Cronbach's alpha based on } \\
\text { standardised items }\end{array}$ & N of vignettes \\
\hline Low altruism $\times$ ST & 0.713 & 0.720 & 9 \\
Low altruism $\times$ LT & 0.710 & 0.725 & 9 \\
High altruism $\times$ ST & 0.788 & 0.793 & 9 \\
High altruism $\times$ LT & 0.920 & 0.918 & 9 \\
\hline
\end{tabular}

Note: $\mathrm{LT}=$ long-term relationship, $\mathrm{ST}=$ short-term relationship

The $2 \times 2 \times 2$ mixed ANOVA on altruism (high vs. low), types of relationship (short-term vs. long-term), and sex (female vs. male) indicated that there was a significant main effect of altruism on respondents' desirability for a relationship $[\mathrm{F}(1,136)=90.642, \mathrm{MSE}=0.341, p<0.001$ (see Table 2)]. There was also a significant main effect of relationship type 
$[\mathrm{F}(1,136)=27.904, \mathrm{MSE}=0.377, p<0.001]$. On the other hand, there was no significant main effect of sex on respondents' preference for a relationship $[\mathrm{F}(1,136)=0.320, \mathrm{MSE}=0.807, p=0.530($ see Table 3$)]$.

Moreover, there was a significant interaction between altruism and relationship length $[\mathrm{F}(1,136)=48.646, \mathrm{MSE}=0.256, p<0.001]$. Descriptive statistics indicated that when altruism was low, there was only a slight difference in preference for a short-term or long-term relationship (see Table 4), and further post-hoc analysis revealed that it was not statistically significant $(p=0.847)$. On the other hand, when altruism was high, there was an increase in preference for a long-term relationship over a short-term relationship (see Table 4). The post hoc analysis showed that the preference for high altruism in a long-term relationship was statistically significantly when compared to high altruism in a short-term relationship $(p<0.001)$, as well as to low altruism in short-term relationship $(p<0.001)$ and low altruism in long-term relationship $(p<0.001)$. Moreover, the preference for high altruism in a short-term relationship also increased slightly when compared to low altruism, which was statistically significantly different to low altruism in short-term relationship $(p=0.005)$ and low altruism in long-term relationship $(p=0.017)$.

However, the two-way interaction between altruism and sex was not significant, $\mathrm{F}(1,136)=2.764, p=0.099$, indicating that regardless of high or low level of altruism in the vignettes, male and female respondents did not significantly differ in their rating (see Table 2). The interaction between types of relationship and sex was also not significant, $\mathrm{F}(1,136)=0.126$, $p=0.723$, suggesting that if altruism is excluded, male and female participants did not significantly differ in their preferences of different relationship types. There was also no significant three-way interaction between altruism, types of relationship and sex, $\mathrm{F}(1,136)=0.267, p=0.606$, indicating that the association between altruism and relationship types was not significantly different in male and female respondents (see Figure 1).

Table 2: $2 \times 2 \times 2$ mixed ANOVA: Tests of within-subjects effects

\begin{tabular}{lrrrrrc}
\hline & $\begin{array}{c}\text { Type III } \\
\text { sum of } \\
\text { square }\end{array}$ & df & $\begin{array}{c}\text { Mean } \\
\text { square }\end{array}$ & F & Sig. & $\begin{array}{c}\text { Partial eta } \\
\text { squared }\end{array}$ \\
\hline Altruism & 30.936 & 1 & 30.936 & 90.642 & 0.000 & 0.400 \\
Altruism*Sex & 0.943 & 1 & 0.943 & 2.764 & 0.099 & 0.020 \\
Error (Altruism) & 46.416 & 136 & 0.341 & & & \\
Relationship & 10.530 & 1 & 10.530 & 27.904 & 0.000 & 0.170 \\
Relationship*Sex & 0.047 & 1 & 0.047 & 0.126 & 0.0723 & 0.001 \\
\hline & & & & & (continued on next page)
\end{tabular}


Table 2: (continued)

\begin{tabular}{lrrrrrr}
\hline & $\begin{array}{c}\text { Type III } \\
\text { sum of } \\
\text { square }\end{array}$ & df & \multicolumn{1}{c}{$\begin{array}{c}\text { Mean } \\
\text { square }\end{array}$} & F & Sig. & $\begin{array}{c}\text { Partial eta } \\
\text { squared }\end{array}$ \\
\hline Error (Relationship) & 51.323 & 136 & 0.377 & & & \\
Altruism*Relationship & 12.445 & 1 & 12.445 & 48.646 & 0.000 & 0.263 \\
Altruism*Relationship*Sex & 0.068 & 1 & 0.068 & 0.267 & 0.606 & 0.002 \\
Error & 34.793 & 136 & 0.256 & & & \\
(Altruism*Relationship) & & & & & & \\
\hline
\end{tabular}

Table 3: $2 \times 2 \times 2$ mixed ANOVA: Tests of between-subjects effects

\begin{tabular}{lcrrrrc}
\hline & $\begin{array}{c}\text { Type III sum of } \\
\text { square }\end{array}$ & df & Mean square & F & Sig. & $\begin{array}{c}\text { Partial eta } \\
\text { squared }\end{array}$ \\
\hline Intercept & 5813.104 & 1 & 5813.104 & 7204.174 & 0.000 & 0.981 \\
Sex & 0.320 & 1 & 0.320 & 0.530 & 0.530 & 0.003 \\
Error & 109.739 & 136 & 0.807 & & & \\
\hline
\end{tabular}

Table 4: Descriptive statistics

\begin{tabular}{lllll}
\hline & Sex & Mean & Std. deviation & N \\
\hline High altruism $\times$ Short-term relationship & Male & 3.1316 & 0.89836 & 65 \\
& Female & 3.2664 & 0.91263 & 73 \\
High altruism $\times$ Long-term relationship & Male & 3.7128 & 0.58955 & 65 \\
& Female & 3.8402 & 0.49655 & 73 \\
Low altruism $\times$ Short-term relationship & Male & 3.0632 & 0.65763 & 65 \\
& Female & 2.9878 & 0.50700 & 73 \\
Low altruism $\times$ Long-term relationship & Male & 2.9983 & 0.63571 & 65 \\
& Female & 3.0046 & 0.50831 & 73 \\
\hline
\end{tabular}

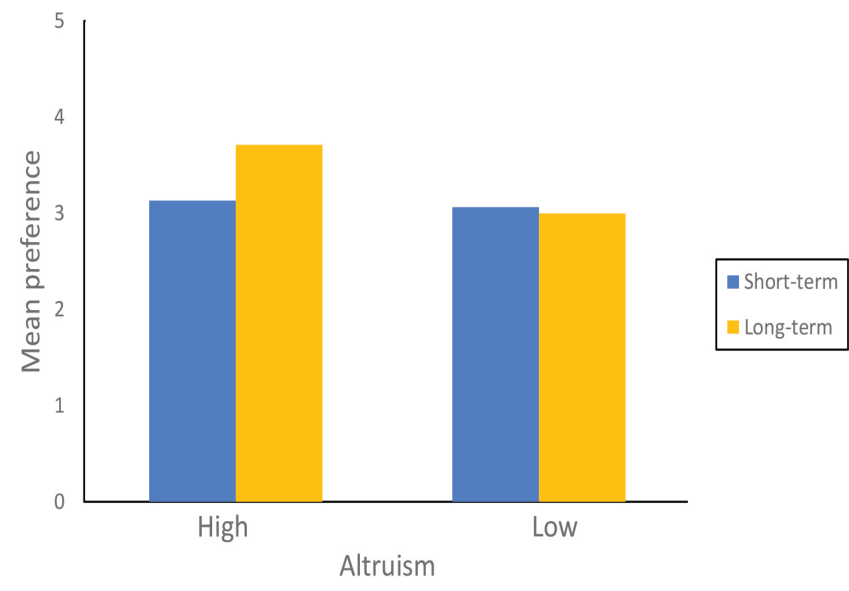

(a) Male

Figure 1: Mean preferences for low and high levels of altruistic partners in long-term and short-term relationships rated by male and female respondents (continued on next page). 


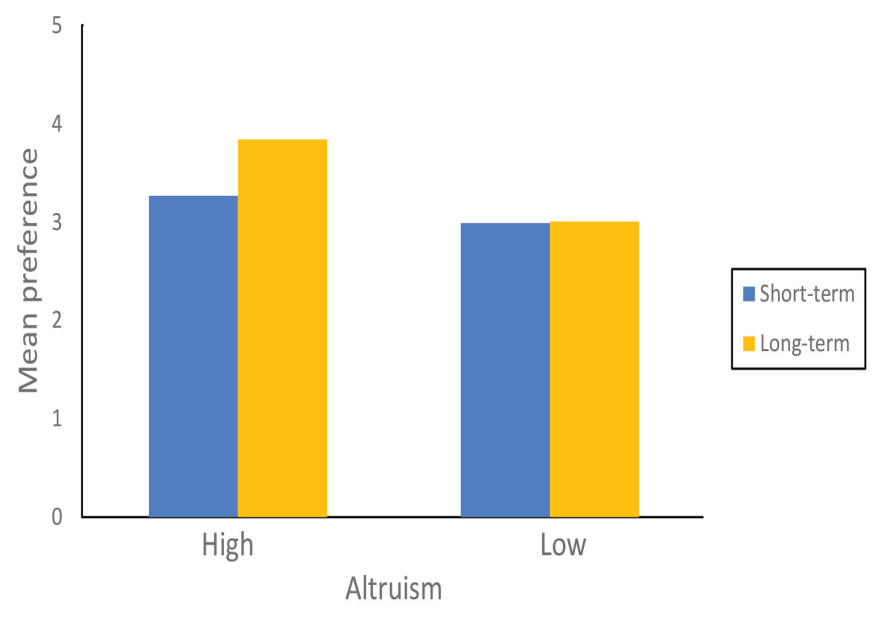

(b) Female

Figure 1: (continued).

\section{DISCUSSION}

The findings from this research add to the literature on prosocial behaviour and mate selection. The results indicate that there is a preference for the individuals in vignettes who exhibited a high level of altruism compared to those who exhibited a low level of altruism. This supports the first hypothesis. Moreover, this preference is greater for a long-term relationship, when compared to a short-term relationship, which supports the second hypothesis. However, males and females did not report different mean ratings, suggesting that both sexes rated the vignettes similarly, thus, rejecting the third hypothesis.

The results indicate that there is a greater preference for individuals who exhibit a high level of altruism which is consistent with previous literature. One possible explanation is the costly signalling theory developed by Zahavi (1977), which described altruistic behaviours as a mechanism for altruists to advertise their desirable resources or personal qualities. The ultimate advantage to the altruist is the increasing chance that he or she will be desired as a partner (Grafen 1990; McAndrew 2002; Zahavi 1977). Moreover, costly signalling can be an indicator of an honest signal. The potential impact of a woman responding to fabricated information concerning her partner's qualities can have a dramatic effect on reproductive success resulting from a lack of investment, an unwillingness to invest or due to low-quality offspring and a non-supportive mate (McAndrew 2019). As a result, there is a selective pressure to develop certain tactics to detect honest signals of quality in potential mates. Sending a signal requires a cost from the sender which is a 
dependable way of proving the honesty of that signal, thus, costly signalling is said to be advertising (McAndrew 2019). Individuals with high mate values possess many resources so they can afford high-quality signals (Grafen 1990). Therefore, costly signalling theory suggests that people often display acts that are costly as a strategy to signal or advertise honest information about the senders.

That desirability for an altruistic partner increased as the length of relationship increased is also consistent with previous research (Margana et al. 2019; Farrelly et al. 2016; Barclay 2010; Moore et al. 2013). An altruistic partner is more important in a long-term relationship because altruism signals numerous positive qualities such as kindness, resourcefulness, and generosity, which are the essential mate qualities (Buss 1994). Kelly and Dunbar (2001) proposed the good-gene hypothesis which suggested that altruism indicated underlying genetic qualities. The ability to survive with a costly handicap and at the same time help others to survive signals something about the individual's underlying genetic quality. An alternative explanation, the caring hypothesis, advocated by Miller (2001) stated that altruistic behaviours suggested an individual's willingness to invest in the relationship and in potential offspring.

Research from the University of Kent supported the good-gene hypothesis and the caring hypothesis (Iredale and Vugt 2009). They asked female participants to watch a video of the same male either giving money to a beggar, donating blood, saving a bag from a thief, or displaying none of these behaviours. They found that females rated the man saving a bag as significantly physically healthier and stronger, which supported the good-gene hypothesis that physically risky and costly altruistic behaviours provide cues about the individual's gene quality. Also, women ranked the man who donated money to a street beggar as more likely to be resourceful. Furthermore, women ranked the man as being more committed to a relationship when he donated blood or money rather than when he saved a bag. This study concluded that bravery oriented altruistic behaviours provide quality gene cues, while monetary aid or volunteering signals the willingness to invest and care in a relationship; thus, altruistic traits are more important in a long-term relationship.

In the current study, the preferences for an altruistic mate do not differ between males and females, which is inconsistent with existing literature (e.g., Phillips et al. 2008; Bhogal et al. 2019a) where studies found that women, more than men, place a greater significance on altruistic traits during mate selection. According to Tessman (1995), a man's willingness to share can provide cues about his commitment and generosity, and that women value men's potentiality to acquire and share resources. Thus, women may 
be more likely to consider altruism as an important trait when selecting a romantic partner. Similarly, Bhogal et al. (2016) also concluded that altruism may have evolved in men as a strategy to attract women by signalling his resourcefulness. Barclay (2010) suggested that women are more concerned with positive characteristics in romantic partners in order to prevent possible abandonment or violence in relationships, but the difference in altruism preferences is reduced in committed long-term relationships.

On the other hand, some research has yielded similar results to the current study in which both females and males favoured altruistic mates for long-term relationship over short-term relationship (Farrelly 2013; Moore et al. 2013; Farrelly and King 2019). The researchers argued that altruism signals positive parental and mate qualities which are valuable to both men and women, especially in bi-parental families where both parents invest significantly (Buss 1994; Phillips et al. 2008; Bhogal et al. 2019b). Thus, it has been suggested that altruism evolved through mutual mate choice rather than solely through female choice, which indicates that both men and women value altruistic traits when they select a mate for a long-term relationship (Farrelly and King 2019; Bhogal et al. 2019b). Nevertheless, Bhogal et al. (2019b) proposed that the varied findings in differences between men and women's desirability for altruistic partners are due to the limitations of the methodologies applied by the researchers.

As the findings from previous research remain inconsistent, the current research aims to emphasise the potential role of culture on altruism and mate selection that is often neglected. For any number of possible reasons, Thai males and females did not vary in the desirability for altruistic partners. One possible explanation is religion. The Buddhist-collectivistic culture may have an impact on selecting prosocial partners. More than $94 \%$ of the Thai population practises Buddhism and the connection between Buddhist concepts and Thai life is inseparable (National Statistical Office of Thailand 2015; Plamintr 1994). Buddhist influences can be found in almost every aspect of Thai culture including mannerisms, language, traditions, architectural design, and the arts (Plamintr 1994). Values associated with Buddhism such as "merit" (bun) and "virtue" (khwaamdii) which emphasise selflessness and compassion may have reinforced the importance of helping others in Thai culture (Hanks 1962). Research conducted to explore the role of pro-sociality in Thailand and the United States concluded that Thais had a greater tendency and willingness to help others than participants from the United States (Yablo and Field 2007). The same study also revealed that Thais attributed religion as 
the reason to help others. Thus, religious beliefs may have reinforced Thais' expectations of altruistic mates in romantic relationships regardless of sex.

As mentioned earlier, one of the reasons for conducting this research is to examine potential cultural variation in altruism. Additional research which examined the cultural differences between the East and the West in relation to the role of altruism in mate desirability and selection is limited yet there are Asia-specific examples. A similar study conducted in China found different results from those conducted by evolutionary psychologists in the West. When Chinese undergraduates chose a partner or advertised themselves to a potential partner, the most important trait was kin altruism rather than general or non-kin specific altruism and reciprocal altruism (Guo et al. 2017). The researchers attributed their results to the impact of filial piety as reinforced by Confucianism which places great importance on collectivism among family members. The study concluded that for Chinese people, maintaining the honour of family and caring for parents signalled better future parental investment (Guo et al., 2017). If an individual respects, obeys, and takes care of the family, it indicates that the individual is more likely to be a responsible partner for the family and future offspring. Similar research from Japan also found that when comparing altruism towards strangers or friends, altruistic behaviours towards kin were more desired, especially in long-term relationships (Oda et al. 2013). The authors concluded that women preferred mates who behave altruistically towards family members in a long-term relationship in order to avoid the distribution of resources to non-kin.

Another variable that could be useful when examining cultural differences in altruism is the influence of collectivism-individualism. Collectivists are a group of interconnected individuals who consider themselves as a whole (Triandis 2018). They value social harmony and the well-being of the entire group. On the other hand, individualistic societies place a greater significance on personal autonomy and self-responsibility. A study conducted by Wagner (1995) explored the influence of individualism-collectivism on the tendency to cooperate. The author found that individualists were less likely to perform cooperative acts, whereas collectivists were more reliant on groups so they tended to be more cooperative (Wagner 1995). Further research bore similar results concluding that collectivism was positively correlated with cooperation, but such a correlation was not found in individualism (Marcus and Le 2013). Munroe (2018) explored children's altruistic behaviours from four different cultures. He found that children from collectivistic cultures were more likely to help others compared to children from individualistic cultures. However, Finkelstein (2010) investigated the role of individualism- 
collectivism in volunteering. The author concluded that individualists and collectivists did not vary in their inclination to volunteer but differed in their motivations to do so. For collectivists, volunteering was more significantly related to humanitarian concerns for others and the promotion of social ties; whereas, individualists were more career orientated (Finkelstein 2010). Therefore, whether individualists or collectivists are more likely to participate in volunteer activity remains somewhat inconclusive.

\section{SIGNIFICANCE AND LIMITATIONS}

The current study contributes to the literature concerning mate choice and altruistic behaviours, especially in Thailand where limited research was done. The entire survey was translated into Thai and Thai psychological assessments were not common. Furthermore, every vignette used in this study was reconstructed to adapt to Thai norms. Consequently, this study does not only contribute to the growing literature concerning mate preference and altruism but also the existing body of research exploring mate preferences among Thais.

Despite the strengths of the current study, some limitations should be noted. First, this research only consists of 138 respondents; a larger sample size should be adopted in order to be considered representative of the Thai population. Some scenarios used in the vignettes might be interpreted as risktaking behaviours (e.g., saving a drowning person) and consequently affected respondents' ratings. Non-random sampling was another limitation of the design. When compared to random sampling methods, non-random sampling usually yields less unbiased and less generalised results (Jager et al. 2017). However, random sampling is far more challenging to execute in terms of financial costs. Convenience and snowball sampling methods are far less expensive, more efficient, and easier to administer; thus, they were adopted in this study. Moreover, this study used a Likert-type scale for collecting responses which might lead to response biases (Greenleaf 1992). Finally, social desirability response bias is another factor that may influence the result of this study. Due to self-presentation concerns, respondents may give lower scores to socially discouraged activities and higher scores to socially preferred ones (Krumpal 2013).

In response to the limitations, we have suggested a few recommendations for future studies concerning mating choices and altruism. To begin with, a greater sample size should be considered in order to yield 
a more generalised outcome. More research should also be done to compare the differences of mate preference and altruism among Asian countries where limited data are available. Moreover, cross-cultural research should be conducted to explore the cultural differences which may indicate the possible effects of sociocultural values on mate selection in relation to altruism. For instance, the cultural background of participants from many nations within southeast Asia should be collected and analysed to report whether the findings are statistically different from the findings available at present.

\section{CONCLUSION}

In conclusion, the findings from this research contribute to the growing literature concerning prosocial behaviour and mate choice. The results show that there is an increase in preference when the individuals exhibit a high level of altruism compared to when they exhibit a low level of altruism. Moreover, this preference is greater in long-term relationships than short-term relationships. However, there is no significant difference between men and women's desirability for altruistic partners. Finally, this research also aims to highlight the importance of conducting research in non-WEIRD nations in order to gain a better understanding of varying patterns of mate selection and the importance of altruism within a specific cultural context.

\section{COMPLIANCE WITH ETHICAL STANDARDS}

This research was conducted following approval of the IRB at Mahidol University (IRB number IRB0001007).

\section{NOTES}

* Somying Tsai received her BSc in Biological Sciences from Mahidol University International College with a specialisation in Biomedical Science and minored in Psychology. She is currently pursuing her MSc in Psychology of Mental Health at the University of Edinburgh. Somying is interested in evolutionary psychology, neuropsychology, and the impact of the COVID-19 pandemic on mental health.

** Douglas Rhein is the Chair of the social science division at Mahidol University International College, where he also teaches classes in psychology and media. He has taught and lived in Southeast Asia and East Asia for more than 20 years. His research interests involve cross-cultural psychology, film analysis and the internationalisation of higher education. 


\section{REFERENCES}

Arnocky, S., Piche, T., Albert, G., Ouellette, D. and Barclay, P. 2017. Altruism predicts mating success in humans. British Journal of Psychology 108 (2): 416-435. https://doi.org/10.1111/bjop.12208

Barclay, P. 2010. Altruism as a courtship display: Some effects of third-party generosity on audience perceptions. British Journal of Psychology 101 (1): 123-135. https://doi. org/10.1348/000712609X435733

Bhogal, M. S., Galbraith, N. and Manktelow, K. 2016. Sexual selection and the evolution of altruism: Males are more altruistic and cooperative towards attractive females. Letters on Evolutionary Behavioral Science 7 (1): 10-13. https://doi.org/10.5178/ lebs. 2016.42

Bhogal, M. S., Galbraith, N. and Manktelow, K. 2019a. A research note on the influence of relationship length and sex on preferences for altruistic and cooperative mates. Psychological Reports 122: 550-517. https://doi.org/10.1177/0033294118764640

Bhogal, M. S., Farrelly, D. and Galbraith, N. 2019b. The role of prosocial behaviors in mate choice: A critical review of the literature. Current Psychology 38: 1062-1075. https://doi.org/10.1007/s12144-019-00308-8

Buss, D. M. 2015. Evolutionary psychology: The new science of the mind. New York: Pearson Education Inc. https://doi.org/10.4324/9781315663319

. 1994. The evolution of desire: Strategies of human mating. New York: Basic Books.

Campbell, N. A., Reece, J. B., Urry, L. A., Cain, M. L., Wasserman, S. A., Minorsky, P. V. and Jackson, R. B. 2015. Biology: A global approach (10th ed.). London: Pearson Education Ltd.

Cronin, H. 1993. The ant and the peacock: Altruism and sexual selection from Darwin to today. Cambridge, England: Cambridge University Press.

Darwin, C. 1874. The descent of man, and selection in relation to sex. New York: Merrill and Baker. https://doi.org/10.5962/bhl.title.46219

Farrelly, D. 2013. Altruism as an indicator of good parenting quality in long-term relationships: Further investigations using the mate preferences towards altruistic traits scale. The Journal of Social Psychology 153 (4): 395-398. https://doi.org/10 $.1080 / 00224545.2013 .768595$

Farrelly, D., Clemson, P. and Guthrie, M. 2016. Are women's mate preferences for altruism also influenced by physical attractiveness? Evolutionary Psychology 14 (1): 1-6. https://doi.org/10.1177/1474704915623698

Farrelly, D. and King, L. 2019. Mutual mate choice drives the desirability of altruism in relationships. Current Psychology 38: 977-981. https://doi.org/10.1007/s12144019-00194-0

Finkelstein, M. A. 2010. Individualism/collectivism: Implications for the volunteer process. Social Behavior and Personality 38 (4): 445-452. https://doi.org/10.2224/ sbp.2010.38.4.445

George, D. and Mallery, P. 2003. SPSS for Windows step by step: A simple guide and reference. 11.0 update (4th ed.). Boston, MA: Allyn \& Bacon. 
Gliem, J. A. and Gliem, R. R. 2003. Calculating, interpreting, and reporting Cronbach's alpha reliability coefficient for Likert-type scales. Midwest Research-to-Practice Conference in Adult, Continuing, and Community Education, The Ohio State University, Columbus, Ohio, 8-10 October 2003. https://www.researchgate.net/ publication/31591315_Calculating_Interpreting_And_Reporting_Cronbach\%27s Alpha_Reliability_Coefficient_For_Likert-Type_Scales (accessed 4 November 2020).

Goldberg, T. L. 1995. Altruism towards panhandlers: Who gives? Human Nature 6 (1): 79-89. https://doi.org/10.1007/BF02734137

Grafen, A. 1990. Biological signals as handicaps. Journal of Theoretical Biology 144 (4): 517-546. https://doi.org/10.1016/S0022-5193(05)80088-8

Greenleaf, E. A. 1992. Measuring extreme response style. Public Opinion Quarterly 56 (3): 328-351. https://doi.org/10.1086/269326

Guo, Q., Feng, L. and Wang, M. 2017. Chinese undergraduates' preferences for altruistic traits in mate selection and personal advertisement: Evidence from Q-sort technique. International Journal of Psychology 52 (2): 145-153. https://doi.org/10.1002/ ijop. 12207

Hanks, L. M. Jr. 1962. Merit and power in the Thai social order. American Anthropologist 64 (6): 1247-1261. https://doi.org/10.1525/aa.1962.64.6.02a00080

Iredale, W. and van Vugt, M. 2009. The peacock's tail of altruism. The Psychologist 22 (11): 938-941.

Jager, J., Putnick, D. L. and Bornstein, M. H. 2017. More than just convenient: The scientific merits of homogeneous convenience samples. Monographs of the Society for Research in Child Development 82 (2): 13-30. https://doi.org/10.1111/mono.12296

Kelly, S. and Dunbar, R. I. M. 2001. Who dares, wins. Human Nature 12 (2): 89-105. https://doi.org/10.1007/s12110-001-1018-6

Krumpal, I. 2013. Determinants of social desirability bias in sensitive surveys: A literature review. Quality \& Quantity 47 (4): 2025-2047. https://doi.org/10.1007/s11135011-9640-9

Latane, B. 1970. Field studies of altruistic compliance. Representative Research in Social Psychology 1 (1): 49-61.

Lee, R. B. and DeVore, I. 1968. Man the hunter. New York: Aldine de Gruyter.

Marcus, J. and Le, H. 2013. Interactive effects of levels of individualism-collectivism on cooperation: A meta-analysis. Journal of Organizational Behavior 34 (6): 813-834. https://doi.org/10.1002/job.1875

Margana, L., Bhogal, M. S., Bartlett, J. E. and Farrelly, D. 2019. The roles of altruism, heroism, and physical attractiveness in female mate choice. Personality and Individual Differences 137: 126-130. https://doi.org/10.1016/j.paid.2018.08.018

McAndrew, F. T. 2019. Costly signaling theory. In Encyclopedia of evolutionary psychological science, eds. Shackelford, T. and Weekes-Shackelford, V. Cham, Switzerland: Springer. https://doi.org/10.1007/978-3-319-16999-6_3483-1

2002. New evolutionary perspectives on altruism: Multilevel-selection and costlysignaling theories. Current Directions in Psychological Science 11 (2): 79-82. https://doi.org/10.1111/1467-8721.00173

Miller, G. 2001. The mating mind: How sexual choice shaped the evolution of human nature. Vancouver, Washington: Vintage Books. 
Moore, D., Wigby, S., English, S., Wong, S., Székely, T. and Harrison, F. 2013. Selflessness is sexy: Reported helping behaviour increases desirability of men and women as long-term sexual partners. BMC Evolutionary Biology 13: 182. https://doi. org/10.1186/1471-2148-13-182

Munroe, R. L. 2018. Altruism and collectivism: An exploratory study in four cultures. CrossCultural Research 52 (3): 334-345. https://doi.org/10.1177/1069397117733450

National Statistical Office of Thailand. 2015. Population by religion, sex and area, 2015. http://web.nso.go.th/en/survey/popchan/data/2015-2016-Statistical\%20tables\%20 PDF.pdf (accessed 24 November 2020).

Oda, R., Shibata, A., Kiyonari, T., Takeda, M. and Matsumoto-Oda, A. 2013. Sexually dimorphic preference for altruism in the opposite sex according to recipient. British Journal of Psychology 104 (4): 577-584. https://doi.org/10.1111/bjop.12021

Pfaff, D. W. 2015. The altruistic brain: How we are naturally good. Oxford, England: Oxford University Press.

Phillips, T., Barnard, C., Ferguson, E. and Reader, T. 2008. Do humans prefer altruistic mates? Testing a link between sexual selection and altruism towards non-relatives. British Journal of Psychology99(4): 555-572. https://doi.org/10.1348/000712608X298467

Plamintr, S. 1994. Getting to know Buddhism. Bangkok: Buddhadhamma Foundation.

Tessman, I. 1995. Human altruism as a courtship display. Oikos 74 (1): 157-158. https:// doi.org/10.2307/3545685

Triandis, H. C. 2018. Individualism and collectivism. New York: Routledge. https://doi. org/10.4324/9780429499845

Trivers, R. L. 1971. The evolution of reciprocal altruism. The Quarterly Review of Biology 46 (1): 35-57. https://doi.org/10.1086/406755

Wagner, J. A. 1995. Studies of individualism-collectivism: Effects on cooperation in groups. Academy of Management Journal 38 (1): 152-173. https://doi. org $/ 10.5465 / 256731$

Wilson, D. S. 2015. Does altruism exist? Culture, genes, and the welfare of others. New Haven, Connecticut: Yale University Press.

Yablo, P. D. and Field, N. P. 2007. The role of culture in altruism: Thailand and the United States. Psychologia 50 (3): 236-251. https://doi.org/10.2117/psysoc.2007.236

Zahavi, A. 1977. Reliability in communication systems and the evolution of altruism. In Evolutionary ecology, eds. Stonehouse, B. and Perrins, C., 253-259. London: Palgrave. https://doi.org/10.1007/978-1-349-05226-4_21 